\title{
A Few Words about Tomasz Sobczak's Easel Painting "You Are an Artist Only from Time to Time" (Mr. Nobody)
}

\author{
Tomasz Sobczak \\ Lodz University of Technology, Poland \\ E-mail address: sobchuck@o2.pl
}

\section{ARTICLE INFO}

\section{Keywords:}

Tomasz Sobczak

Energy of painting

Genius of attempt

Painting

\section{Article history:}

Received 01 September 2014

Received in revised form 10 January 2015

Accepted 17 August 2015

ISSN: 2354-0036

DOI: 10.1515/ctra-2015-0024

\section{A B STRACT}

The energy of a painting is born with every brush stroke. The vitality, the acerbity, the distance, the record of emotions in general - these are only a few elements of the reality in which a PAINTING is born. In the likeness of fulfilment together with the projection of dreams. A unique diary of passing thoughts that are written within a line and a dab, thoughts that would never find their way to a recipient if not for the genius of an attempt. An attempt to register a mood, the moments when one looks for respite, together with the moments infused with the fever of the creation of answers to a question of the order and the harmony. The meaning of creation, constant in its message. Give the best you may and can give, and you will get even more. May you, dear sir, keep living in a creative and unique way! May you, dear lady, keep living in a creative and unique way!

Instinct, intuition, passion, emotions, intellect, experience and a few other ingredients that make up the mysterious concoction pompously called creative activity

When I wonder to what extent my painting has come true, I realise, although not entirely, what huge reservoirs of energy can lie in every brushstroke. And I mean the time when a painting is being created, then looking at the finished and creatively employed surface, and finally its completely independent existence. And then there is the confrontation of the substance on the canvas with some important event. A good or a bad experience. It does not really matter. And so I find traces of a prophecy in every patch of colour, and I go back to the moment when a shaped colour was seeking its place on a canvas that had just been started (being filled with the form and substance of thoughts and hunches). And the constant existence of an impression, which is paradoxical, of how much new power we can get from every trace left on a canvas.

It is difficult to start from some hard fact when you are trying to comprehend the time span between the first timid attempts that copied works of other painters and the latest 
painting, made right after my return from England. Also an important and long-awaited one. After the welcoming one there were more, but that first one, finally in my own studio, was very important. It was a comeback to myself. To my inner feelings. Although there, in the land of Albion, I did paint too, but with hindsight I recollect those miniatures as timid excursions and attempts to hear my own thoughts. And not only my own. They were filled with a great longing, full of memories of the time that started to go by so quickly. Giving no respite or hope that the moments devoted only to painting could still come back. And it all started when I felt...

...the primal and intuitive rapture with more or less successful copies, and then there was only the quest for the Golden Fleece that has been continued until today. Such was the beginning of the still lasting adventure. Tempera still lifes painted on cardboard, pencil sketches which, after so many years, are an invaluable mark of my search for satisfaction from doing the activity that once managed to awaken my interest enough to become, with time, an inseparable life companion, even when circumstances did not let me reach for a canvas or dip a paintbrush in the magical element of paint squeezed out onto a palette. Whenever I could memorise or sketch something "till later". This is how a ritual was slowly being born, and mounting with minor activities...

...A ritual of preparations for painting a picture that has not changed so much over these twenty-five years. Once favourable conditions occur to go ahead with a new a painting, I start with tidying up my studio. I put away all unnecessary things, I meticulously hush all noises around me in order to get the necessary space, and when the table has finally been emptied, I bring out a box of paints onto a white table top. Before I start, I always buy some extra tubes of zinc white and titanium white. Plus several favourite colours, just in case I run out of them. And of course a few paintbrushes. The flat ones with hard bristles. Once the paints are squeezed out onto a palette, all the fun starts with mixing linseed oil and turpentine, and with various kinds of media. To make a mixture that works properly and whose consistency is appropriate. A few jugs, a paint brush holder, and everything is ready. Several goes with mixing a colour, and off to work. And of course music, my faithful life companion, is necessary, but I will write about that later. I remember precisely when I made...

...My first "still life", painted on an old, slightly tilted frame. A still life whose charm I see in the simplicity of its form and the search for a result. My attempts to render the effect of glowing lemon yellow as best as I can, emanating energy on the background of green tissue paper, and brush strokes, still inadept and missing some lightness and skill, while the layer of paint that was being applied lacked some turpentine and linseed oil. The enticing smell of turpentine and all mixtures whose presence lasts and will never cease 
to do so. They are still present in my memories. For one reason only. It is my world. Why mine? I have built it with my own hands. Why has it happened? I will try to write about it, although I know that it is no mean feat to depict simple activities in an interesting literary form, activities that are far from being magical to an outsider. Many actions based on intuition and emotions are supposed to change into words. This text will be an attempt to name everything. Well, almost everything. I remember that...

...At first there was the instinct to immortalise something in the form of a painting made by hand, an imitation. With every consecutive painting, it was becoming a more and more thought-out artistic construction. But in every phase and at every stage of my painting, the world of creation was splitting up and mingling with instinct, later and in a nobler way called intuition and intelligence. The first traces of a brush and the impressions of a discoverer. Primal and fascinating. First afterthoughts and conclusions, the criticism of many observations and plans for the future. The blissful state of ignorance which was becoming an experience with every stroke of a paintbrush...

...And no one knows when the time came for philosophy. The earliest, which only recorded events, and another that, by describing consecutive phases, started organising the next paintings and prophecies on many levels and various surfaces. When, using still new signs, I tried to tame them, believing in their existence and appreciating their meaning, I slowly started to sense what a new world I was just welcoming. As if a man instinctively wanted to reach for a system of values that had not existed before. Whose existence he was only anticipating and listening out for its coming. Knowing the existing common values, taken from those reigning and dominating over the unbelief of some religions, I provoked myself to looking from a closer perspective at a system of values in a brand new configuration...

...To the religion of a painting. Yes, it is true. Every canvas needed faith. Firstly, in the fact that it could come into being, then, that it had brought some news and a message. All that in order to be able, in the course of the years, to look at myself in a mirror of events and confront the reality of a painting with a day gone by. The faith in my ability to leave a mark behind me has unintentionally become my pagan religion. Because if we go on like this...

...Greek philosophers were putting together the first texts and the faith was becoming philosophy and religion at the same time. At first, something small sprang to their minds. An idea maybe? It later led them to the realisation that this thing had arisen from something bigger, which, in turn, had arisen from something even bigger, and so on. Until the collapse of the Hellenic culture. Yet still there is Seneca, Plato, Sophocles, and other prominent tutors of tyrants and rulers. The latest sometimes exist on the cards of the history of vileness only thanks to their contacts with the genius of their teachers, and some- 
times completely inefficient mentors. One of them was the first. Just like my...

...First painting was supposed to become the beginning of an adventure, whose part took place only in the imagination. In emotions. An all-life adventure. Before the first one was created, the tour around the imagination had already been ongoing. Destiny? This is what I thought until today. But is it only this?

I cannot prove that I have always wanted to be engaged in the fine arts. My desire goes back to the tender age when the image of my father comes back. His hands were as big as loaves of bread, and he copied, in a wonderful and light manner (at least for me at that time), the illustrations from the chapter entitled "Harvest" of the Falski ABC book. Never again did he manage to impress me more. Now, after so many years, I regard it as the most important event and performance in my life.

Except the finality that his death was. Although in that act he was alone. And there was no admiration from me. Only regret and sorrow, as nothing had been explained, and he died in a state of unawareness.

Once I tried to find the origin of my engagement in the fine arts. Today, I cannot tell you everything, or the whole truth yet. I think I am not able to. But this is how it was.

Many hours spent over drawings I did not have to make. I desperately wanted to. It was the only reason. But...

...Sometimes, when my memories go back to a specific painting, from this wad uncoils a thread of thoughts that sometimes do not fall into place. But for me they are most important. Actually, only a specific painting seems to speak of the present and the future. The origins of the inception of this concrete thing? It is always the same. The curiosity of how I am going to cope with my emotions of a discoverer, a revolutionist, who, in a bloodless manhunt after myself, finds exactly this form of answers to many questions. Issues that circulate around my head like a mad carousel whose spinning nothing can stop. Okay, maybe only the next painting, and just for a while. This is why I find satisfaction in a finished painting. A painting in the image of my ego, imagination and the reality that has become an aesthetic fact. When the brushes have been put aside, and the canvas says, "Enough," I realise that I have just become a partner of the big mystery of the birth of a picture, which is a proof, and a living one, that a secret exists, and it is the joy of overcoming all the resistance of matter as well as spiritual infirmity. Transcendent connection with the outer space during which there was nothing just a moment ago. It is obvious, and now, step by step, rhythm by rhythm, stroke by stroke, the leaven of the next decisions is created. Because isn't it marvellous that several traces left on the canvas become an inspiration for the succeeding steps, sometimes more courageous or even mad. I regard myself as "a painting beast", a creature that with its sense 
of smell and all the other senses feels and instinctively guesses the next proper and infallible steps turned into the decisions of an independent patch of a freedom island.

My first ever oil painting - a still life, as well as the latest painted - and not only painted, but also conceived from the first rhythm to the last brush stroke - they both have created the present balance of my spirit. Both of them were initially made by means of the beginnings of an alphabet of shapes, forms, colours, up to a language full of well-known secrets which I can use until this day with such great desire and ease. This is how it has worked for years. The most...

...Fascinating was experiencing to what extent the "unknown" pushed me into other spaces, all locked in the canvas two dimensions. Initially, there were the first tentative attempts, when rather awkward forms and shapes were created. Then, giving them the colour, what is more, looking for the most appropriate tone. A passion, yes, a passion for discovering everything that is unknown. Mixing reflections on the latest experiment with the initial intention. An idea and its representation. At that time I felt it was quite a challenge. What inspiration! Now and then, I would peer at a shy sketch on a sheet of paper.

And the most paradoxical desire to be unique at all times. This is why I could not seriously take up graphic art or other replication techniques. Only once, and never again, to approach myself, to enter the deepest parts of the nature of my ego and my expectations. To let instincts seize me, to entrust a moment to fate and the unknown. And only on the occasion of this very painting. The next one will be a new challenge and another one-off adventure. Although created with a similar language and narration, even the cycles that I have up my sleeve are unique and a surprise for myself.

And an unbelievable thing. A kind of a prophecy. Paintings, predictions, whose meaning emerges in the more distant and immediate future. A prophecy, or maybe specifying the future. Setting the marks that only time will imprint.

Metaphysics, fortune-telling, although not superstitions. It is the time of setting myself a goal and the way forward. When it turned out that I had not achieved my goal, I was not always disappointed with the outcome. The way I had gone was more important. Adventures and anecdotes worth experiencing. Like...

...Meeting the people whose presence I have recorded in my paintings, the simplest stories and the most complicated feelings, whose significance I still cannot estimate. Maybe it is better when some mystery remains. Similar to the one that is encapsulated in music. It was thanks to music that I would cross every longed-for border of country $X$ or $U$, and I would learn the cadences of the sensitivity of remote tribes and nations. This sensitivity would fill me with impressions that were able to propel the imagination. Exactly... 
...And finally music, whose beginnings in my paintings I am unable to realise. At various stages it was different sound media that accompanied me in my peregrinations through the land of ease and liberty. Without it and its influence some paintings might never have been born. Some others would have been completely different. The most important feeling that has accompanied me in my painting adventure is the state of joy of discovering. The exciting moment of learning a new reality. Its fragments that were only coming into existence. An inspiration with the sounds that, what with their existence and their source in emotions and intellect assisted by talent, sometimes genius, are an inseparable companion in my creative process. Many times I have had the impression that everything I hear exists for some reason. Instinctively listening out, I had the impression that, in a mysterious way, I was approaching the secret of creating a specific tune, the shining of truth in music, which is recorded in a language of abstraction. All music signs, when read only, are the silence around, while in my head there is music, and a harmony is being created whose meaning in an abstract way moves to a canvas with Mozart-like lightness. Maybe Vivaldi-like? And the omnipresent perversity that, being supported with many memorised paintings by masters and of reality, did not let me copy or repeat something. Everything had to be started anew. If I was enraptured with Kandinsky or Bacon paintings, I would look, step by step, for the soul of those anxieties or the joy of creation in my own paintings. The state that I have always needed is the joy of discovery, even if the beginning was sorrow, a desire or a quandary, on a more serious occasion called a lifelong problem, a dilemma.

In these peregrinations of my imagination I have been accompanied by a musical layer. Even now that this text is being created, in my ears there is humming jazz that belongs to the best of the worlds. To the world of abstraction of musical notation and the sound whose interpretation is obvious proof that all artists are looking for only one type of philosopher's stone - harmony. Sometimes it is regardless of the price and the cost of sacrifices, turning unfulfilment into fulfilment, fear into certainty of brush strokes, filling the emptiness with a colour that is irreplaceable and inimitable in any subsequent painting.

I instinctively believed, I intuitively trusted that the time of solitude with a painting represents moments that are filled with passion and fulfilment which are most important for the intellect and emotions. The physical contact with the matter of a painting, the smell of turpentine, linseed oil and mixtures made out of a need to obtain even more effective phrases of a painting. With the full awareness of the consequences that result from the uniqueness and primal strength of a newly created formula of a painting's faces, which uniqueness and primal strength took up residence in my brain once the painting had been finished. With time, my initially naïve distance mixed with admiration has become the cer- 
tainty that I exist in multiple dimensions, of which painting is one of the most important. The art of creating a painting. Writing a book of senses, lined with defiance of a more and more experienced rambler in an endless space. A space woven from the everyday life of many actions and unfulfilled desires, however happily fulfilled in the frozen form of a painting to which it is enough to give a name. By some people called a title. A noble one, if anything. Because noblesse oblige. I sometimes feel it when I still hear some traces of conversations long after they are finished. And then I have the impression that it is only the hum of words about nothing, words that are unimportant and meaningless. But if these words of little value were hosted in my ego for some time, it was only because I did not want to sound with a similar quality or paint about nothing. This is why the seeming structure of the abstraction to which I am so faithful gives me a motive to freely invent canvases for new events and painting props to surface. To intertwine these canvases with threads of the new names of the patches and outlines on them.

And so, painting by painting, the dictionary is expanding, the dictionary of my painting expressions. Sometimes epithets thrown towards a specific address. And later, while looking at a painting, can a viewer say that he or she has encountered an epithet? What a comfortable state it is to be able to try to convert the world with the art of one painting. The motif of conversion? I have heard about it before. This is why...

...The next chapter comes from the contrariness, a natural one, in connection with curiosity. It is the distance to all religious regulations and canons of faith which, by doctrinally incorporating man's naivety into hard rules, let him believe that faith had chosen just him. The contrast between material poverty and the spiritual wealth of the Dalai Lama, and its reverse in the case of the Christian religion, has turned me into the most cautious gnostic, that I reluctantly call myself. Because when I look up the pages of the history of philosophy, and I encounter so much openness that existed in the Hellenic culture, I realize how poor God's intellectual field is. This one and only God. When I follow the story of Fatima and the prophecies that took place there, I cannot resist the temptation to visit that patch of land. Unfortunately, I am afraid that commercialisation has beaten the miracle of a prophecy, and has been turned into a local economic miracle. This is when, like a "da capo al fine" motif, back comes the thought that I know what I need. A canvas and the silence. So that I can name my phantasmagorias.

One by one, and then the next ones. By their first names. Because names of paintings, or their titles, are a separate topic.

When I look at many paintings, everything starts to spin faster around me, and at the same time a lot calms down in me. Such a paradox. It's not the first time and not the last. A space for the next painting decisions is created, and the paintings themselves pay 
me a visit like most welcomed guests. Inside the walls of the studio where I have come to spend more than twenty-five years.

There was a time, right after my graduation, when I did not think about painting. I saw other goals, I had other plans. Restoration of antiques, film scenography, writing short literary forms. Prose, poetry. Sometimes cartoons.

Finally, photography. It too, has captured my interest like any artistic material that enables fascination to be registered. But after some time a thought crystallised in me that only one form of exhibition and creation makes me fully content, as well as intellectually and spiritually richer. Also morally, even if I was perpetrating a shameless painting with an implied erotic meaning right at that time. I felt what the catharsis meant. The key word when, right after finishing a painting, I feel like a newborn baby. With a new energy and zest for life, and a new space in my emotions to be filled. Just like this...

...The state of my soul and my mind whose results I cannot overestimate. It was art that became my most effective shield, armour, although not weapon. Even if I wanted to name this state of existence, I would not be able to. Because it is only a struggle with myself. It is a fight with my own weakness and temptations that are passing, if only for the reason that no trace of them would have been left in the space of my material culture if not for the notes on various backgrounds. Because "naming" is conferring a contour, colour and shape on a particular patch or outline. In my paintings, photographs, drawings and texts, I leave "new names" based on both my intuition and previous experience. Because it is...

...My paintings that look at me. Although only from time to time, but still. And dealing with them puts me in the mood for reflections, and every time when our meeting is on, because somewhere deep inside I can hear a call and a request for the next child. Because they are my children that I let out into the world the moment they were born. Irrational metaphysics? Maybe. And even if there is someone who will deny this, there is nothing wrong with it. Because it is from doubt about the existing status quo and the state of the matter that the next proofs of material culture arise. Also from the fascination and enchantment with some absolutely real situation. And then every painting is a story. Shorter or longer. Playful digressions, provocations, comments on the reality that are woven into the warps of the gift of the lightness of painting and a strand of narration, which, even years later, is able to remind me of the origins of initially one thought, a shining, to later transform itself into the finiteness of matter. And yet...

...At the beginning of my painting there was concrete and so called representational painting; still lifes, several portraits and landscapes. And right after those first attempts there was an afterthought that it had all happened before. Therefore, is speaking someone else's language worth wasting time on? Repeating after somebody? As my reaction 
of protest and contrariness, the first canvases, awkward at that time, but how priceless today, were created. This is how the adventure started that has lasted until this day, only with intermissions for ordinary life. The adventure of learning myself. Of my painting and technical abilities, and stimulating creative power. Maybe even vitality? Paintings, once they have materialised, invoke a desire to exist. No one knows how they affect my perception; I can see further and more. It is as if they were taking off my glasses made from habits and everyday routine.

Why am I mentioning this? Because to me they are most important. Only then comes the era of the viewer. The time of confrontation with mundane reality, so-called taste and erudition, hopefully, it is true. A man who is a stranger to these paintings, a man who may find a harmony similar to mine.

But it may also be the case that he will reject some painting because he has decided that it is only chaos, and he has not noticed any positive values. Any meanings. I do not even say, "Tough luck, I didn't manage to take him to the canvas," on such occasions. Each of us has been through many such appointments. Does it prove anything? Yes, that my thoughts are unique and a construction that makes a harmony so fresh and new, that even I myself cannot find enough expressions to form a comment. I do not know how, and it is fine. Because there is something above a word. It hasn't been named, but it can be sensed and guessed forever.

It is a mystery. A secret whose meaning I cannot overestimate. It is the darkness that mysteriously unfolds a fairy tale, a short story, and a painting. It gives such meetings a unique character. The mystery does not need to appear in gloomy paintings. It appears in all the places where, despite having all happened before, the materialisation of elements, planes, and figures (that are completely unexpected both in terms of form and content) creates the aura of a mystery, and thus of discovering it as a consequence. We are all attracted to this journey into the unknown. It is not important how big or how small a mystery it is. When there is something we do not know, it is this state of consciousness in unconsciousness. What a paradox! The mystery has got powerful strength which pushes ahead towards unknown areas. Even if it is risky, some of us make the effort, and although they sometimes pay for it with their lives, they cannot act in a different way. Just like this. While pacing up and down the still empty spaces in my paintings, I listen and wait for the moment that will bring me the answer. Even the most impossible, and impossible to be named, one that becomes the face of the year, month, week and day that I started brooding over yesterday's unfinished session of painting. By academics called easel painting. And yet some of my paintings are created on such huge formats that I have had to give up traditional easels and now I stretch canvases like 
the wings of an enigma bird. And this is a real challenge. A square of canvas, a sea of white, and unknown spaces that need to be given a rhythm. Sometimes even barbaric when I cut the canvas with strokes of a brush that has been dipped in the grey of the paint, with just some light ochre added. Only to wait for the next suggestions of my own universe that has been changed into another rhythm and detail. Or maybe it was Daedalus, he who has been remembered by many people until this day for his heroic deed. The escape that made him immortal. The liberation that also brought disaster the death of his only son Icarus. Maybe this is why...

...I have not mentioned a very important thing yet. The fact of how significant painting has become for me through the mere fact of creating either in silence or not, but always alone, in isolation, the state to which I initially could not become accustomed, then I got to like it, and over time it finally developed into a long wished-for companion of my peregrinations through imagination. This most important promise of fulfilment that no one can touch, spoil, or, what is worse, take away. It was a very special silence that arrived for the first time while I was drawing something that I do not even remember. And it is not important, after all. The fulfilment came alongside with the welcoming of the silence. I finally heard my own thoughts, the emotions found the appropriate rhythm of their visualising, waiting patiently for their turn. I believe that the huge impact of painting on my selfesteem became an accomplished fact a long time ago, except that I did not notice this obvious relationship for a long time. And it was not important whether a person accepted what I had painted or not. What counted was the fact that I had decided something, and then I sacrificed my time, energy and something else. Talent - something I have not mentioned before. Because what is talent? Manual skills or something else, deeper in its phenomenon of creation. Or auto creation, if you prefer. The feeling of a complete liberty in creation, despite many everyday restrictions, is a marvellous prize whose values change from painting to painting and from meeting to meeting. They add up and intermingle. In this passion of creating...

...I have never been able to believe in team art creation. To me it has got an air of swindle that I associate with many a boat, in which only one oarsman is left. I have checked this status quo many times, and I still do not believe in such creations. The history of art and the fate of many masterpieces strangely calm me down. Painting has especially been gripped by such intimate and individual rigour since the dawn of the human race, when the first men created the first trace, just by making a picture, maybe with a stick on the sand, or on some other occasion, with a clubbed animal's blood on a person's face or on the rocky floor of their cave that, paradoxically, many artists give the art of painting the highest position among all other creative arts. As with writing this text - 
it needs concentration and "silence". And the presence of music can wonderfully and very efficiently enclose me in a symbolic ivory tower. It is the only substance whose company I need. In the sense of purity and the need for ascesis. This magical interfusion of sounds which rush to meet the unknown. I scrutinise the thoughts that run along an unpredictable stream of consciousness, and I improvise. With a conviction that it is only now that such a confrontation, which gives the desired content, may occur. But why the canvas and oil painting? Because, like no other matter, they give me the sense of complete fulfilment. Until the total exhaustion of emotions and infinite fatigue, when the paintbrush says, „Enough,” and the canvas proudly settles back in its final form, relaying some content, a surprise message. Because challenging a painting whose beginnings were in the white surface of a canvas is the invariable hope of creating of another mystery, a surprise. The hope of discovering another important value in my life. And even if I happen to feel the end of my life approaching, I will prepare my only legacy: a pile of paintings, of which I hope to make many more. For one reason only. Because it is the most important part of my being in this mortal coil. If, while creating this text, I first heard in my thoughts, and then saw, a few new expressions concerning painting in general, then I was led to them by my earlier paintings, as well as those that had not even been started. The ones I am thinking about, and I know they will happen in my life.

Thanks to them dreams are becoming the most beautiful reality. Because it is a unique reality. Mine. I can remember an exhibition at which I could not be present for a few reasons. At first, there was regret that gave way to certainty that I had been there, all uncovered like the upper surfaces of the twelve canvases bearing a collective title - "The valley's last will". Exhibitionism. When I got them back after a few years, my only concern was whether they were "safe and sound". I will never forget the feeling I had while opening a package with them inside in my studio.

Another funny paradox of creation is the moment of interest from a person who wants to buy a specific painting. At first, it is pride with a little vanity, then fear, even grief. How can that be? Am I supposed to give over my perfected and successful child to a stranger just like that? The price becomes a minor issue, and the conversation becomes tiring. And it is always like that. I do not even want to repeat the thoughts that absorb me then. At such moments I envy musicians-composers, as nobody can take away from them even a tiniest part of their work. How can one come to terms with the thought of a parting? A very difficult matter.

This is how negotiations have ended up many times - a painting stayed with me for longer. I am very happy that most of them are here with me. It is so good to keep in my mind... 
...Nine empty stretchers, for example. Not more than two months ago I was making preparations to move a part of my studio to a new place. To the huge and comfortable basement of a pre-war tenement house. I had prepared most of the paintings to be transported, and at some point I reached the wall of the storeroom, and saw a few pretty large stretchers leaning against it. I counted nine of them. I carried them, one by one, and looked at each with concern. Had they stood the test of time? Were they ready to be covered with canvas? I thought that it was a marvellous promise, and also a portent of the creation of more secrets, in which I would find other incarnations of harmony and order. And the conviction that I would not find them anywhere else. Nothing I had recently done, no thing I had bought myself, no photography or computer gadgets of my dreams had ever given me so much joy as finding these nine stretchers. I felt it was a matter of destiny. The joy of being this primal painting beast that had been discovered in me by my first oil painting. This is why, for numerous reasons and with numerous undertones, I associate the seemingly strange sounding acronym...TBC.

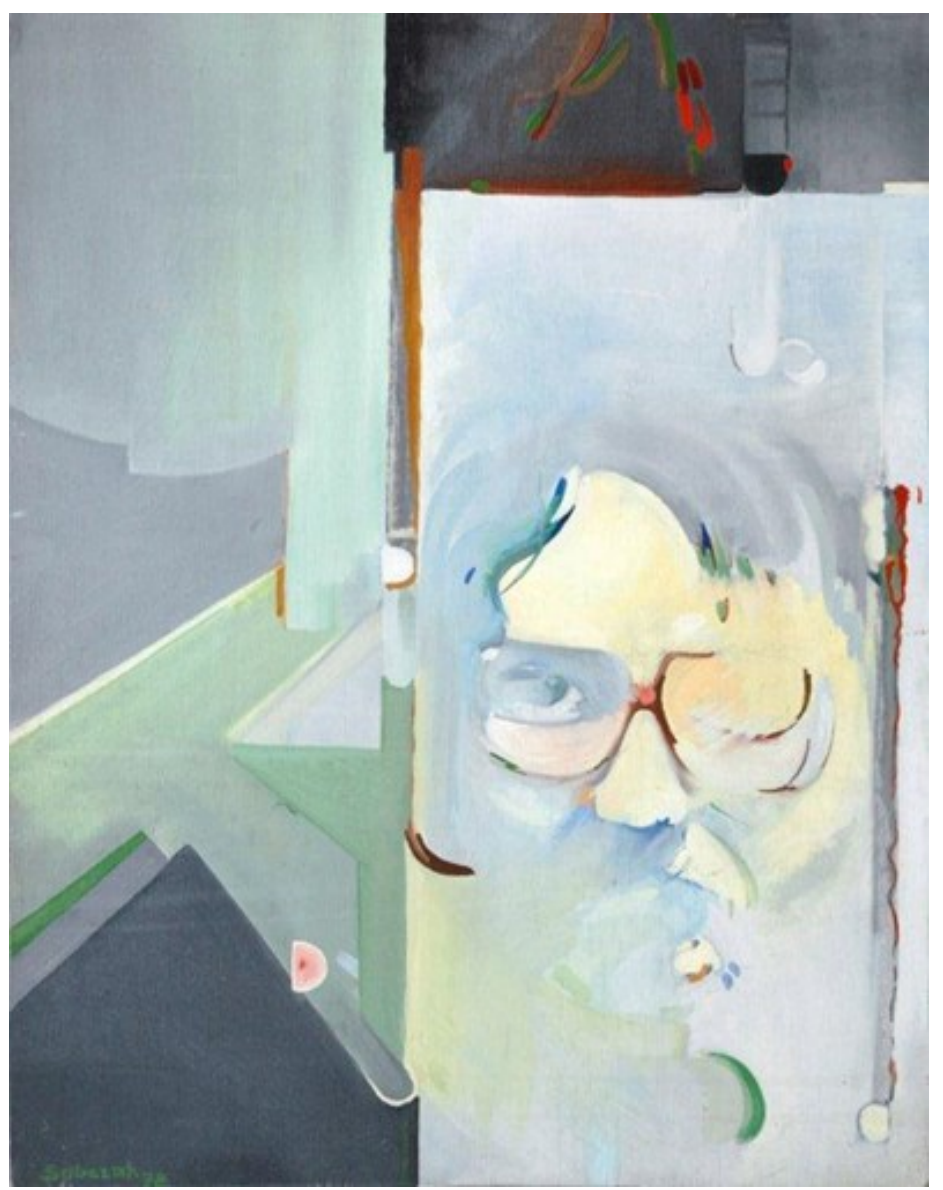

Tomasz Sobczak (1977). Self-portrait 


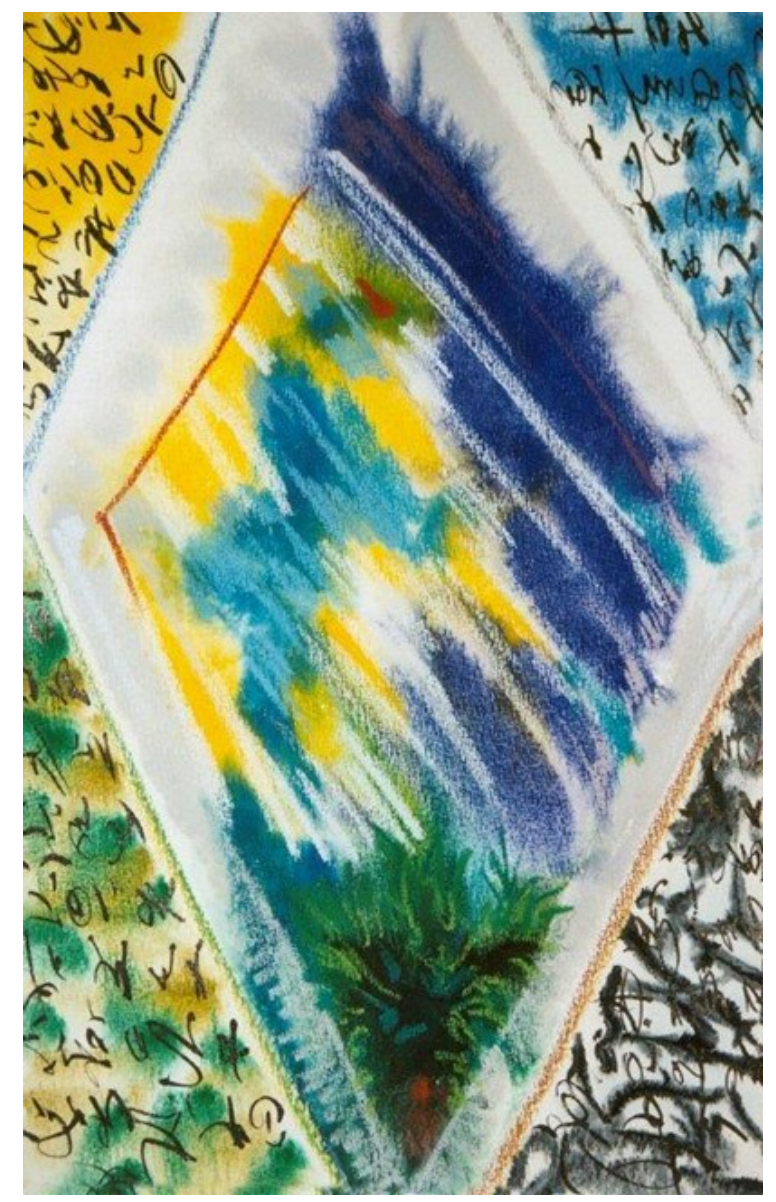

Tomasz Sobczak (1986). Desire

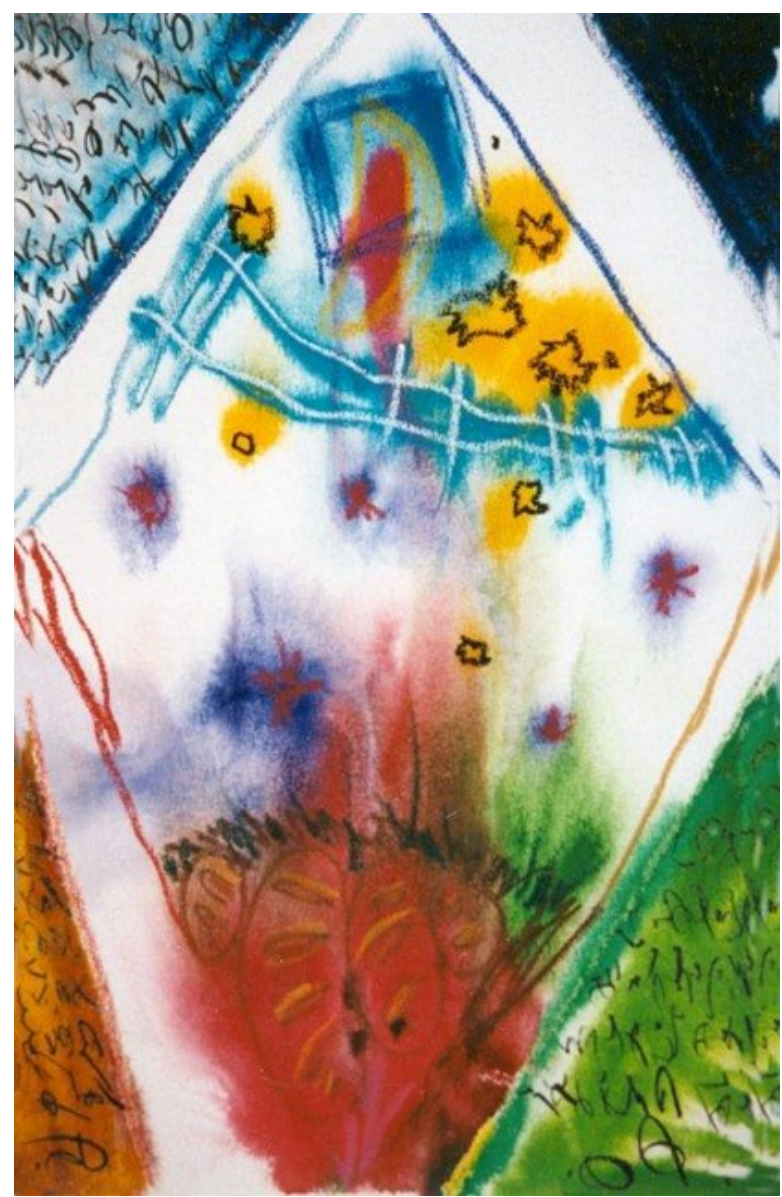

Tomasz Sobczak (1986). Desire 


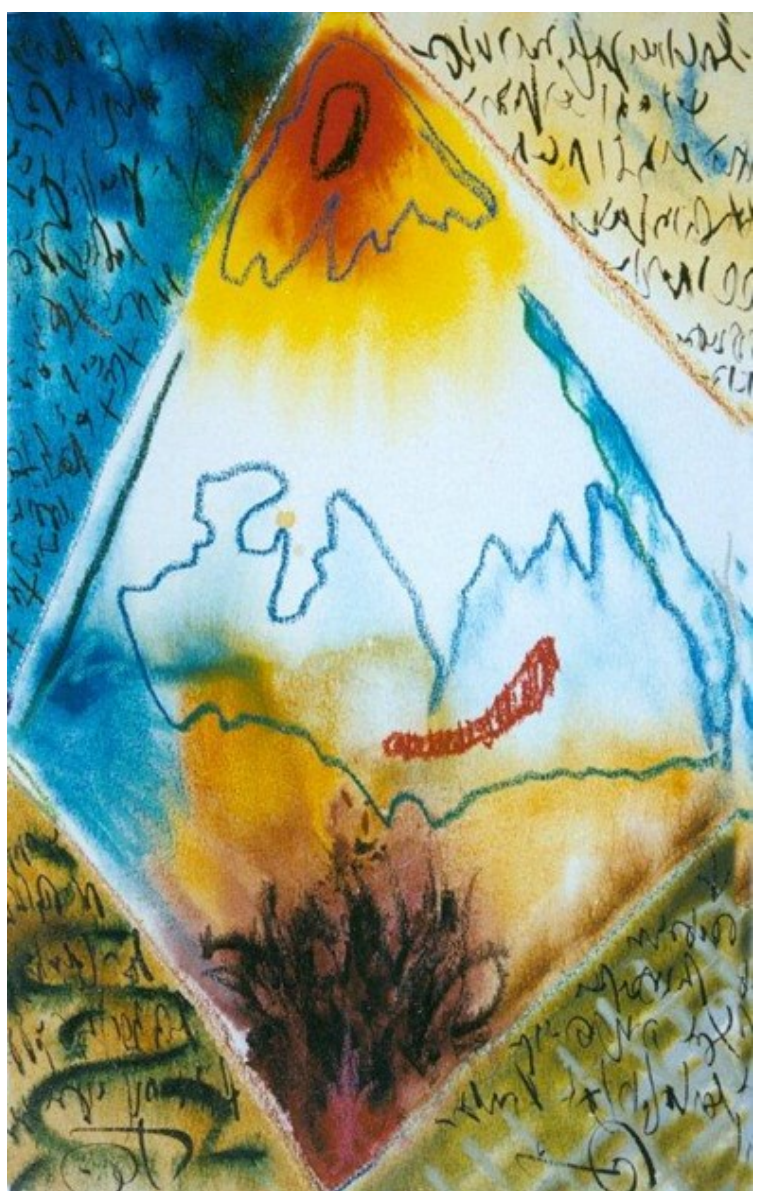

Tomasz Sobczak (1986). Desire

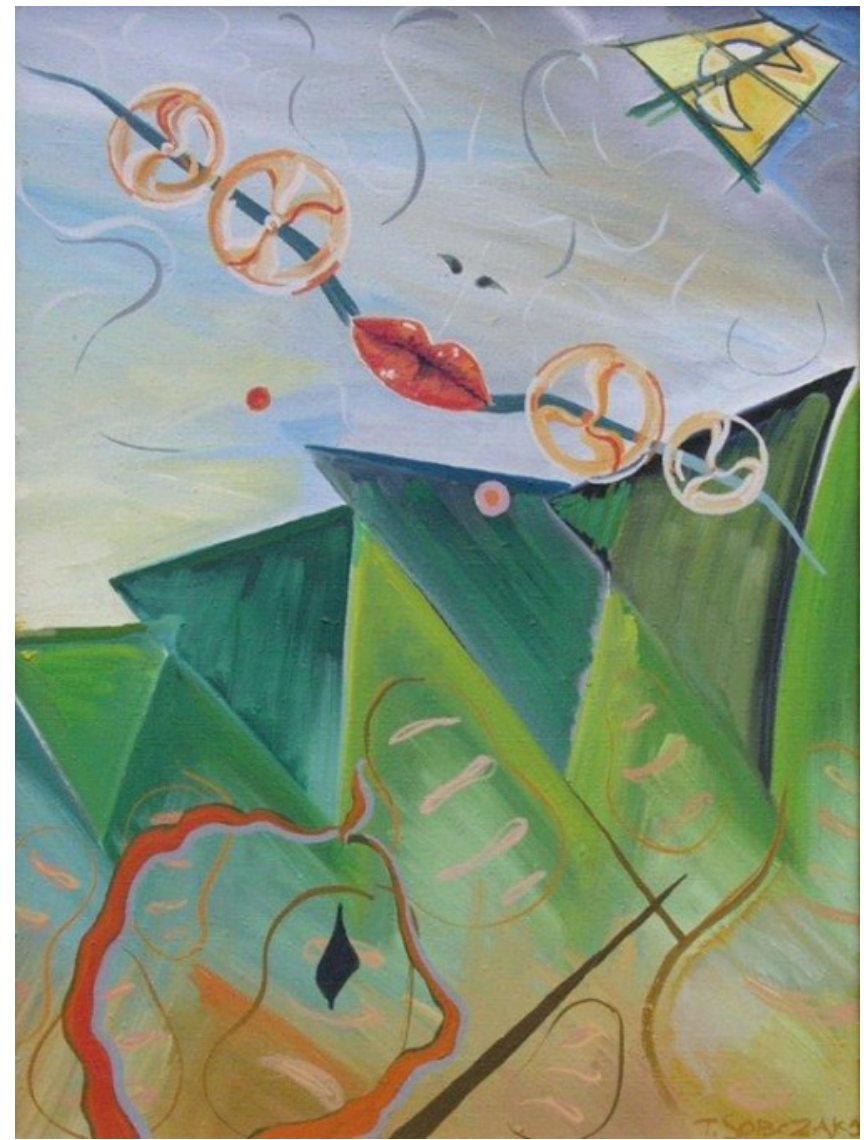

Tomasz Sobczak (1987). A tempting flight 


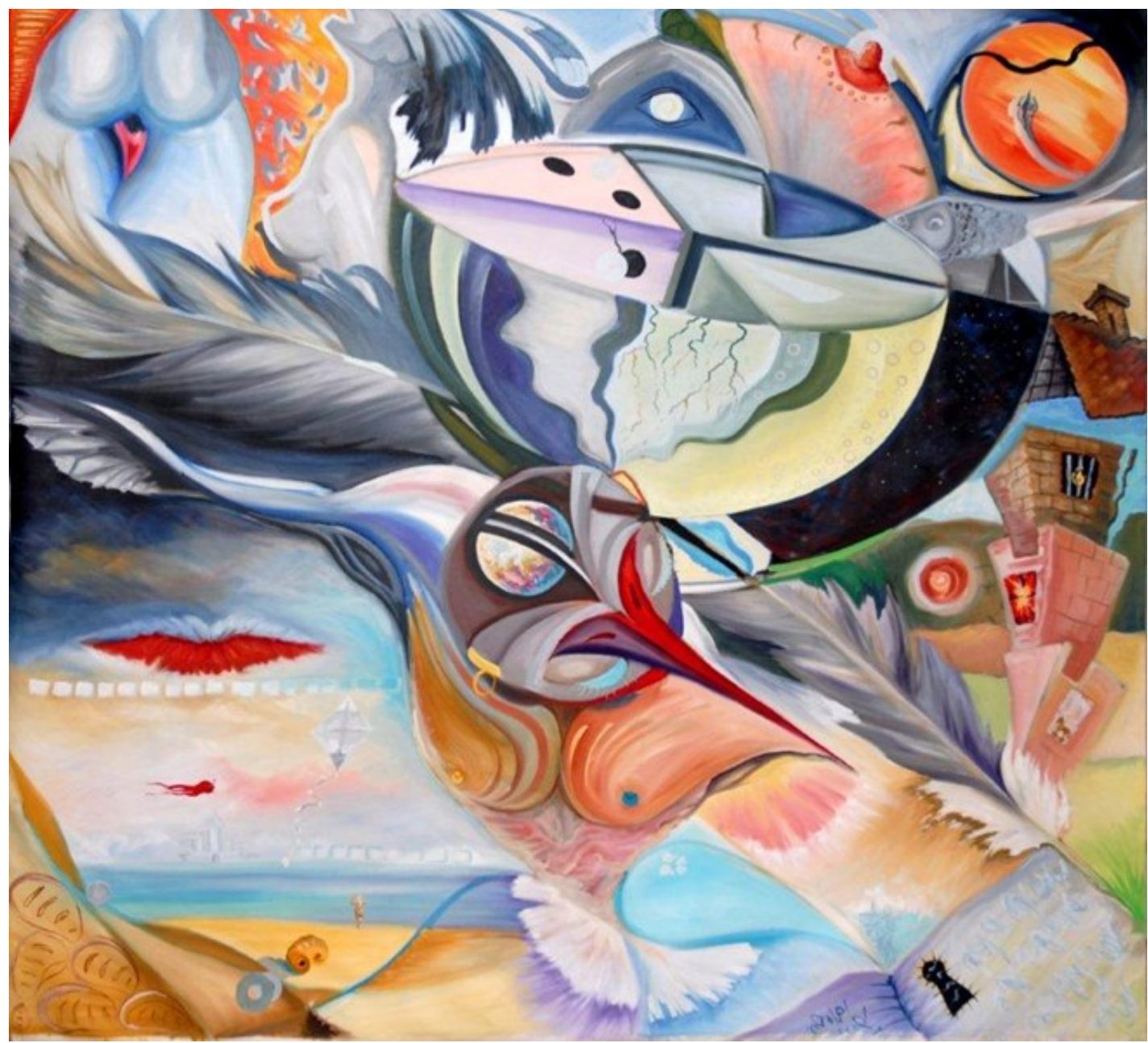

Tomasz Sobczak (2006). The return of Odysseus

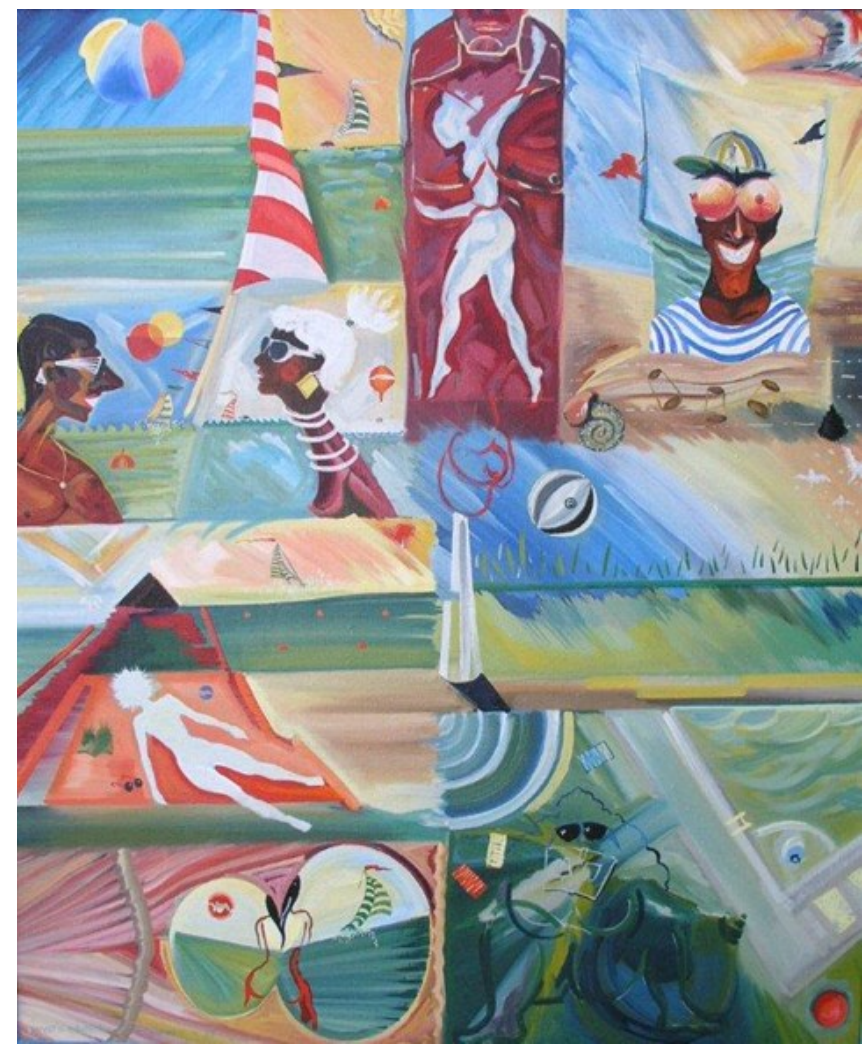

Tomasz Sobczak (1987). Summertime 


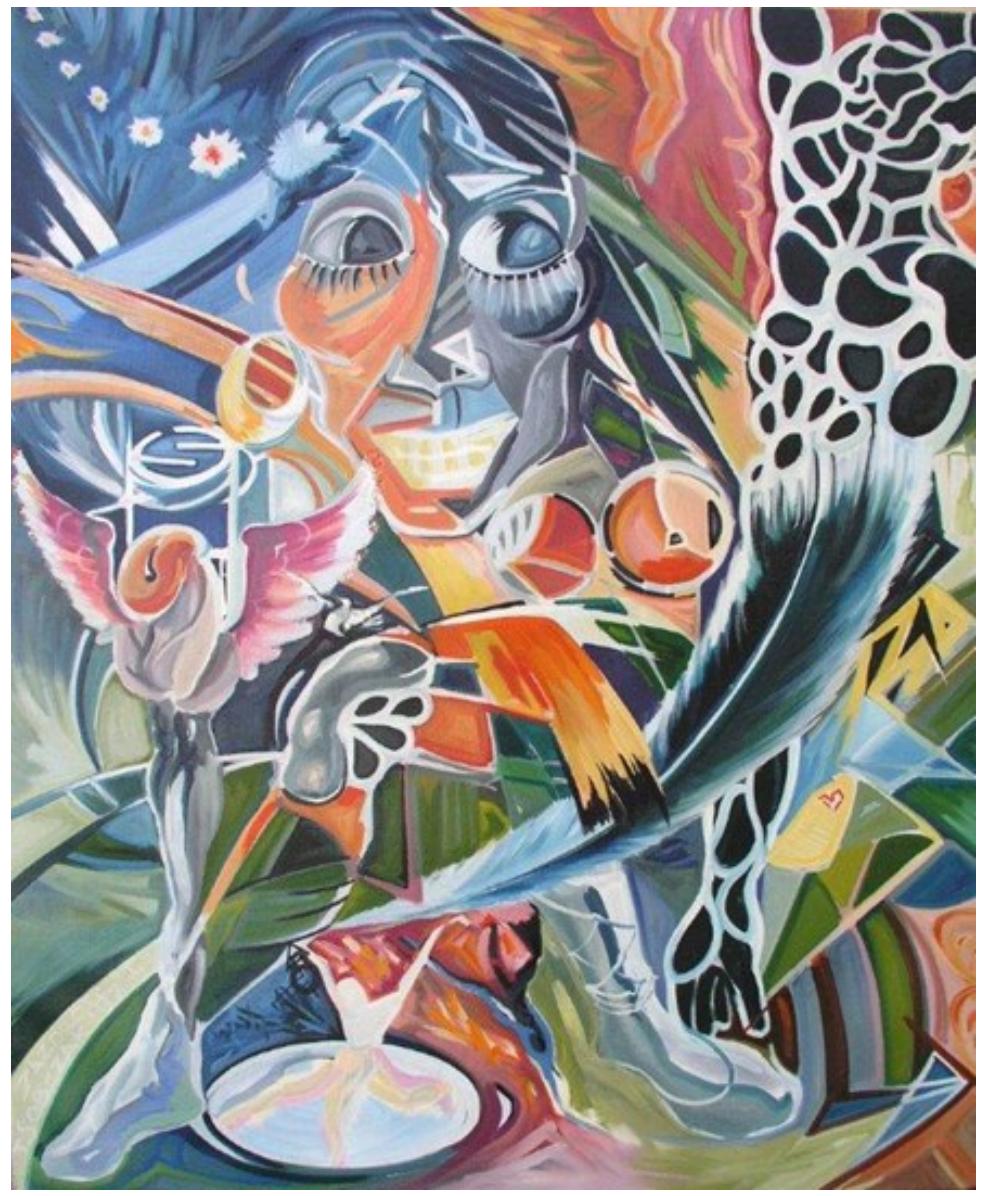

Tomasz Sobczak (1988). Jealousy

Corresponding author at: Tomasz Sobczak, Faculty of Material Technologies and Textile Design, Lodz University of Technology, 116, Zeromskiego St., 90-924 Lodz, Poland E-mail: sobchuck@o2.pl 